\title{
Cryptococcal eosinophilic meningitis in a patient with sarcoidosis
}

\author{
Hiba Hadid, ${ }^{1}$ Paul Nona, ${ }^{2}$ Muhammad Usman, ${ }^{3}$ David Paje ${ }^{1}$
}

${ }^{1}$ Henry Ford Health System, Detroit, Michigan, USA ${ }^{2}$ Wayne State University, Detroit, Michigan, USA ${ }^{3}$ Internal Medicine Department, Henry Ford Health System, Detroit, Michigan, USA

\section{Correspondence to} Dr Hiba Hadid, hhadid2@hfhs.org

Accepted 28 November 2015

\begin{abstract}
SUMMARY
A 51-year-old African-American man with underlying pulmonary, hepatic and splenic sarcoidosis, reported a 3day history of headache, neck stiffness and photophobia. He was not using medication for chronic sarcoidosis. Physical examination was significant for nuchal rigidity. Lumbar puncture revealed marked eosinophilia in the cerebrospinal fluid, which, on further analysis, demonstrated a positive cryptococcal antigen. HIV antibody and PCR tests were negative. Bronchoscopy and fungal blood cultures were also negative. The patient was started on amphotericin B and flucytosine, with significant clinical improvement. He recovered well without any neurological sequelae and remained symptom-free at 2-week follow-up. Cryptococcal central nervous infections are uniformly fatal if left untreated. Prompt diagnosis and treatment is essential, to prevent the associated high morbidity and mortality.
\end{abstract}

\section{BACKGROUND}

Eosinophilic pleocytosis of the cerebrospinal fluid (CSF) is a rare, distinctive finding that is often indicative of certain helminthic infections of the central nervous system. Non-helminthic causes are rare but well documented in the literature. Cryptococcosis is an opportunistic infection that typically affects immunocompromised patients. Cryptococcal eosinophilic meningitis is unusual, with few cases reported. Sarcoidosis is an idiopathic, systemic, granulomatous disorder that has been described as an independent risk factor for cryptococci infection. The impairment of cell-mediated immunity, and treatment with steroids and other immunosuppressive medications, are thought to be the main culprits for the increased risk of acquiring opportunistic infections in these patients. We report a unique case of a patient in whom an uncommon infection was manifested by an atypical presentation (eosinophilic pleocytosis) in the setting of an unusual, but well-described, risk factor (sarcoidosis).

\section{CASE PRESENTATION}

A 51-year-old African-American man presented with a 3-day history of nausea, vomiting, neck stiffness, photophobia and a gradually progressive, diffuse, throbbing headache. The patient's medical history was significant for hypertension and a seizure disorder secondary to bleeding cavernous malformations that were resected two decades earlier. The patient also had a history of biopsyproven lung, liver and spleen sarcoidosis diagnosed 10 years previously during a hospitalisation for bile duct obstruction. Owing to financial and compliance issues, the patient never started any chronic treatment for his sarcoidosis. The patient's social history was negative for alcohol, tobacco, and over-the-counter and recreational drug use. His long-term medications included levetiracetam $500 \mathrm{mg}$ twice daily and atenolol $50 \mathrm{mg}$ daily. $\mathrm{He}$ had no significant travel history in the past year; however, 2 years prior, he had travelled to multiple states, including Georgia, Louisiana, California and Alabama. He was employed as a truck driver and denied any recent sick contacts or contact with any animals or wildlife. The patient was not on any immunosuppressive medications and denied any risk factors for HIV. He had no previous exposure to tuberculosis and no history of incarcerations. On physical examination, the patient had vital signs within normal limits. Neurological examination was significant for nuchal rigidity. Kernig's and Brudzinski's signs were negative. His mentation was intact and there was no evidence of focal neurological deficits. Routine blood work revealed a complete blood count and comprehensive metabolic panel within the normal reference range. A non-contrast CT scan of the head showed no acute pathology.

\section{INVESTIGATIONS}

Lumbar puncture revealed normal glucose of $44 \mathrm{mg} / \mathrm{dL}$, elevated protein of $108 \mathrm{mg} / \mathrm{dL}$, a red blood cell (RBC) count of 1969 cells $/ \mathrm{mm}^{3}$ and a white cell count of $1826 \mathrm{cells} / \mathrm{mm}^{3}$ with a corresponding differential of $76 \%$ eosinophils, $14 \%$ neutrophils, $7 \%$ lymphocytes and 2\% monocytes. Opening pressure was not obtained during the initial lumbar puncture. CSF and blood cultures were collected, along with ACE levels. CSF samples were analysed to rule out tuberculosis, fungal infections, viruses, parasites, syphilis and Lyme disease. Although the patient had no abdominal symptoms, given the marked eosinophilia in the CSF, stool samples were obtained to rule out parasitic infections. Owing to the xanthochromic appearance of the CSF, CT angiography of the brain, followed by MRI of the brain and entire spine, was performed. HIV, aspergillus galactomannan and complement test results were normal. The cryptococcal antigen was positive. Subsequent ophthalmology examination revealed no ocular involvement. Immune cell function assays as well as T-helper/suppressor cell analysis were also obtained. CT of the chest and bronchoscopy were performed to determine if there was any cryptococcal pulmonary 
involvement. Fungal blood cultures were collected to rule out disseminated infection.

\section{DIFFERENTIAL DIAGNOSIS}

Given the significant RBCs in the CSF, there was initial concern for an intracranial bleed from cavernous angiomas. CT angiography of the brain did not reveal any acute bleeding. Owing to the patient's history of cavernous angiomas of the brain and his high risk for vascular malformations in the spine, MRI revealed several small non-bleeding cavernous angiomas of the thoracic spine. Although there was high concern for an active bleed, evidence did not suggest bleeding from any of the malformations and further work up was not warranted. We also had a high index of suspicion for neurosarcoidosis as the cause of this patient's symptoms; however, MRI of the brain refuted this possibility. ACE level in the CSF and blood were within the acceptable reference range. Given the marked eosinophilia in the CSF and the lack of a plausible explanation, we attempted to identify possible alternative causes. Stool and CSF samples ruled out helminthic infection. CSF samples ruled out viral, bacterial, mycobacterial and fungal infections. Given that the patient was not on any new medications, the possibility of drug-related eosinophilic reaction was eliminated. CSF India ink prep was negative and no organisms were seen. On day 2, cryptococcal antigen came back positive at a titre of 1:2. Given this atypical presentation and the presence of an opportunistic infection, an immunodeficiency work up was conducted. Total helper CD4 count was found to be 328 cell/ $\mu \mathrm{L}$ (\%T-helper CD4 of 31\%), with CD4: CD8 ratio of 1 . Immune cell function assay was found to be severely low at $24 \mathrm{ng} / \mathrm{mL}$ ATP $(<225 \mathrm{ng} / \mathrm{mL}$ ATP signifies low immune response). Disseminated cryptococcal infection due to T-cell immunodeficiency from underlying sarcoidosis was the concluding diagnosis. Fungal blood cultures remained negative. Despite the lack of respiratory symptoms in our patient, disseminated cryptococcal infection from a primary lung source was considered. A CT of the thorax showed diffuse, tiny nodular opacities in the lungs bilaterally in a tree-in-bud configuration, with relative sparing of the lower lobes. Although these findings were similar to previous imaging obtained many years prior, bronchoscopy with biopsy was performed to rule out primary lung cryptococcal infection. Final results were consistent with sarcoidosis with no evidence of infection.

\section{TREATMENT}

After obtaining the initial lumbar puncture, the patient was empirically started on broad spectrum coverage with vancomycin, ceftriaxone and acyclovir. The patient remained symptomatic and required large amounts of narcotics to control his symptoms. He refused a repeat lumbar puncture to alleviate symptoms and to measure the opening pressure. When the cryptococcal antigen proved positive, treatment was tailored with amphotericin B at a dose of $5 \mathrm{mg} / \mathrm{kg} /$ day and 5 -flucytosine at a dose of $25 \mathrm{mg} / \mathrm{kg} /$ dose every $6 \mathrm{~h}$. The patient remained in significant discomfort from continued headaches and agreed to undergo successive therapeutic lumbar punctures. The second lumbar puncture was performed on hospital day 4 (opening pressure of 35 , closing pressure of 19) and the third lumbar puncture on day 8 (opening pressure of 22, closing pressure of 5 ), the latter of which was negative for cryptococcus antigen (table 1). Eosinophilia in the CSF trended downward with treatment but had not resolve completely when the patient was discharged. Interestingly, his RBC count in the CSF significantly diminished, raising the hypothesis that the elevated RBC count was related to the active infection. With successive lumbar punctures and antifungal treatment, the patient showed significant clinical improvement and had a complete resolution of his symptoms and headache after 1 week of treatment.

\section{OUTCOME AND FOLLOW-UP}

After several days of amphotericin B, the patient's creatinine increased 30\% from baseline and remained elevated despite adequate fluid therapy. Given his complete resolution of symptoms, low initial cryptococcal titres and no remaining evidence of cryptococcal antigen, the decision was made to proceed to consolidative therapy. The patient was transitioned to high-dose fluconazole $(1000 \mathrm{mg} /$ day) for 10 weeks, followed by maintenance therapy with $200 \mathrm{mg} /$ day for 6-12 months. The patient remained asymptomatic and was discharged home on hospital

Table 1 Analysis of cerebrospinal fluid samples obtained from the patient on hospital days 1, 4, and 8.

\begin{tabular}{|c|c|c|c|}
\hline & Hospital day 1 & Hospital day 4 & Hospital day 8 \\
\hline Tube \# & 4 & 4 & 5 \\
\hline Volume & 3.0 & 2.5 & 5.0 \\
\hline Colour & XANTHOCHROMIC & RED & Colourless \\
\hline Clarity & HAZY & Hazy (A) & Clear \\
\hline Spun appearance & XANTHOCHROMIC & Clear & Clear \\
\hline Glucose, CSF (40-80 mg/dL) & 44 & 51 & 50 \\
\hline Protein, CSF (15-55 mg/dL) & $108(H)$ & $66(H)$ & $60(H)$ \\
\hline $\mathrm{RBC}(0 / \mathrm{cu} \mathrm{mm})$ & $1969(H)$ & $5074(\mathrm{H})$ & $33(H)$ \\
\hline WCC (0-5/cu mm) & $1826(H)$ & $301(H)$ & $133(H)$ \\
\hline Neutrophils (0-6\%) & $14(H)$ & $15(H)$ & 6 \\
\hline Basophils (0\%) & $1(\mathrm{H})$ & 0 & $1(\mathrm{H})$ \\
\hline Eosinophils $(0 \%)$ & $76(H)$ & $61(H)$ & $64(H)$ \\
\hline Lymphocytes $40-80 \%$ ) & 7 (L) & $18(\mathrm{~L})$ & $28(\mathrm{~L})$ \\
\hline Macrophages $(0 \%)$ & 0 & 0 & 0 \\
\hline Monocytes (15-45\%) & $2(\mathrm{~L})$ & $6(\mathrm{~L})$ & $1(\mathrm{~L})$ \\
\hline \multirow[t]{2}{*}{ Mononucleates (15-45\%) } & $0(\mathrm{~L})$ & $0(\mathrm{~L})$ & $0(\mathrm{~L})$ \\
\hline & Crypto antigen positive & Crypto antigen positive & Crypto antigen negative \\
\hline
\end{tabular}

CSF, cerebrospinal fluid; RBC, red blood cells; WCC, white cell count. 
day 11. On follow-up with the infectious diseases clinic 2 weeks postdischarge, the patient appeared well and had no recurrence of symptoms. He was scheduled to follow-up with pulmonary medicine for discussion of starting treatment for sarcoidosis.

\section{DISCUSSION}

Eosinophilic meningitis is a subtype of meningitis defined by the presence of 10 or more eosinophils $/ \mu \mathrm{L}$ in the CSF or eosinophilia of at least $10 \%$ of the total CSF leucocyte count. ${ }^{1}$ The most common cause of this condition is invasion of the central nervous system (CNS) by parasitic infections. ${ }^{2}{ }^{3}$ Some fungal infections such as coccidioides immitis could also present with eosinophilic pleocytosis. ${ }^{4}$ Non-infectious causes such as medications, ventriculoperitoneal shunt malfunction, autoimmune disorders affecting the CNS and haematological malignancies, have also been linked to this disorder. ${ }^{5-11}$ CNS infections with cryptococcal organisms have been rarely associated with eosinophilic pleocytosis. ${ }^{12}{ }^{13}$ Cryptococcal infections occur most commonly in HIV patients but can also occur in immunocompetent non-HIV individuals. Risk factors for cryptococcosis include inhalation of bird droppings (especially pigeons), immunocompromised status, diabetes and patients with underlying cellmediated immunodeficiency. ${ }^{14}$ Although uncommon, sarcoidosis has been established as an independent and important risk factor for development of CNS cryptococcosis. This association appears to occur regardless of the use of steroids or immunosuppressive drugs, although their use may play a role in facilitating the dissemination of the infection. ${ }^{15}$ The diagnosis of CNS cryptococcosis can be made by detecting the encapsulated yeast form of the fungus in the CSF using India ink stain. This method is quick and easy, and immediately available on obtaining the CSF sample; however, it is only 50\% sensitive in HIV-negative patients. An alternative method for diagnosis of CNS cryptococcosis can be made by detecting a cryptococcal antigen. The antigen is a sensitive and specific marker, and can be detected in the serum and CSF samples of infected individuals. ${ }^{16} 17$ When cryptococcosis of the CNS is diagnosed, prompt treatment is essential to prevent high morbidity and mortality associated with this disease. Although differences exist in the treatment duration between HIV and non-HIV patients, the general treatment plan is the same, consisting of three stages: induction, consolidation and maintenance therapy. Amphotericin B (5 mg/kg intravenous daily) plus flucytosine $(100 \mathrm{mg} / \mathrm{kg} /$ day orally in four divided doses) are the mainstay of therapy. This regimen is usually continued for 2-4 weeks, depending on the immune status of the patient, and response and prognosis. This is followed by consolidation therapy with 400-800 mg fluconazole daily. To prevent relapses, maintenance therapy with fluconazole $200 \mathrm{mg}$ /day should be continued for at least 6-12 months. ${ }^{18} 19$ Given the high intracranial pressures usually associated with this infection, consideration should be made to perform successive lumbar punctures to relieve high intracranial pressures associated with this disease and to assess the response to therapy in all individuals. ${ }^{18}$ Although these are general guidelines, a balance must be achieved when dosing these toxic drugs between clinical benefits and adverse effects in an individual patient. In our patient, we chose to make the switch to fluconazole early to avoid further kidney toxicity. This strategy was based on our patient's excellent initial clinical response, complete resolution of symptoms, low initial cryptococcal antigen titres, HIV-seronegative status, and his negative CSF and fungal blood cultures. These results signified a low cryptococcal load, making an early switch to oral, less toxic therapy justifiable, and spared the patient further unnecessary side effects.

\section{Learning points}

- Eosinophilic pleocytosis of the central nervous system is an unusual finding and is usually indicative of invasive parasitic infections. Cryptococcal infections are an extremely rare cause of this condition and should only be considered when other more common causes have been ruled out.

- Sarcoidosis, if present, should be regarded as an independent risk factor for cryptococcal meningitis in an apparently immunocompetent host, regardless of the use of steroids.

- Cryptococcal central nervous infections are uniformly fatal if left untreated. Prompt diagnosis and treatment of cryptococcal central nervous system infection is essential to prevent the high morbidity and mortality associated with this disease.

Competing interests None declared.

Patient consent Obtained.

Provenance and peer review Not commissioned; externally peer reviewed.

\section{REFERENCES}

1 Kuberski T. Eosinophils in cerebrospinal fluid: criteria for eosinophilic meningitis. Hawaii Med J 1981:40:97-8.

2 Slom TJ, Cortese MM, Gerber SI, et al. An outbreak of eosinophilic meningitis caused by Angiostrongylus cantonensis in travelers returning from the Caribbean. N Engl J Med 2002;346:668-75

3 Bosch I, Oehmichen M. Eosinophilic granulocytes in cerebrospinal fluid: analysis of 94 cerebrospinal fluid specimens and review of the literature. J Neurol 1978;219:93-105.

4 Ragland AS, Arsusa E, Ismail Y, et al. Eosinophilic pleocytosis in coccidioidal meningitis: frequency and significance. Am J Med 1993;95:254-7.

5 Asperilla MO, Smego RA Jr. Eosinophilic meningitis associated with ciprofloxacin. Am J Med 1989;87:589-90.

6 Quinn JP, Weinstein RA, Caplan LR. Eosinophilic meningitis and ibuprofen therapy. Neurology 1984;34:108-9.

7 Kessler LA, Cheek WR. Eosinophilia of the cerebrospinal fluid of noninfectious origin: report of 2 cases. Neurology 1959;9:371-4.

8 Traynelis VC, Powell RG, Koss W, et al. Cerebrospinal fluid eosinophilia and sterile shunt malfunction. Neurosurgery 1988;23:645-9.

9 Weingarten JS, O'Sheal SF, Margolis WS. Eosinophilic meningitis and the hypereosinophilic syndrome: case report and review of the literature. Am J Med 1985;78:674-6

10 Hollister D, Clements M, Coleman M, et al. Eosinophilic meningitis in Hodgkin's disease: report of a case and review of the literature. Arch Intern Med 1983:143:590-2.

11 King DK, Loh KK, Ayala AG, et al. Eosinophilic meningitis and lymphomatous meningitis [letter]. Ann Intern Med 1975;82:228.

12 Schmidt S, Reiter-Owana I, Hotz $M$, et al. An unusual case of central nervous system cryptococcosis. Clin Neurol Neurosurg 1995;97:23-7.

13 Pfeffer PE, Sen A, Das $S$, et al. Eosinophilia, meningitis and pulmonary nodules in a young woman. Thorax 2010;65:1066, 1085.

14 Desalermos A, Kourkoumpetis TK, Mylonakis E. Update on the epidemiology and management of cryptococcal meningitis. Expert Opin Pharmacother 2012;13:783-9.

15 Bernard C, Maucort-Boulch D, Varron L, et al. Cryptococcosis in sarcoidosis: cryptOsarc, a comparative study of 18 cases. QJM 2013;106:523-39.

16 Tanner DC, Weinstein MP, Fedorciw B, et al. Comparison of commercial kits for detection of cryptococcal antigen. J Clin Microbiol 1994;32:1680-4.

17 Hansen J, Slechta ES, Gates-Hollingsworth MA, et al. Large-scale evaluation of the immuno-mycologics lateral flow and enzyme-linked immunoassays for detection of cryptococcal antigen in serum and cerebrospinal fluid. Clin Vaccine Immunol 2013;20:52-5. 


\section{Rare disease}

18 Perfect JR, Dismukes WE, Dromer F, et al. Clinical practice guidelines for the management of cryptococcal disease: 2010 update by the Infectious Diseases Society of America. Clin Infect Dis 2010;50:291-322.
19 Dromer F, Bernede-Bauduin C, Guillemot D, et al. French Cryptococcosis Study Group. Major role for amphotericin B-flucytosine combination in severe cryptococcosis. PLOS ONE 2008;3:e2870.

Copyright 2015 BMJ Publishing Group. All rights reserved. For permission to reuse any of this content visit http://group.bmj.com/group/rights-licensing/permissions.

BMJ Case Report Fellows may re-use this article for personal use and teaching without any further permission.

Become a Fellow of BMJ Case Reports today and you can:

- Submit as many cases as you like

- Enjoy fast sympathetic peer review and rapid publication of accepted articles

- Access all the published articles

- Re-use any of the published material for personal use and teaching without further permission

For information on Institutional Fellowships contact consortiasales@bmjgroup.com

Visit casereports.bmj.com for more articles like this and to become a Fellow 